\title{
The Impact of Human Development on the Standard of Living in Alleviating Poverty: Evidence from Africa
}

\author{
Benjamin Korankye, Xuezhou Wen, Easmond Baah Nketia, Godson Kweitsu
}

\begin{abstract}
The African Union 2030, 2063, and beyond strategic, focused on transformative economic growth and regional integration, empowering the populace and consolidating peace and society cannot be achieved without considering human development as synergies in elevating these policies. A large focus on empowering the populace through domestic credit can help this agenda be realized. For robustness sake, the researcher developed both subjective and objective measures to check the various relationships of the variable that helps to achieve the standard of living. Using data from the World Bank's development indicators and Human Development indicators from 1998 to 2017, the researcher examined human development reduces poverty. In this meta-analysis, the study empirically synthesizes a total of four African countries under study, fixed and random effects estimation, domestic credit and human development study find out these variables have a positive relationship of poverty which helps to improve the standard of living. The findings of this study have important implications for policy implementation and therefore, helps to improve the standard of living in the four countries under study.
\end{abstract}

Index Terms - Poverty alleviation, Human development, Standard of living, Panel data.

\section{INTRODUCTION}

The human development index has been improved since the 1990s for most African countries and this has been a big transformation in economies. Current studies attest to factors that human development is a key factor when it comes to economic growth. Other studies also corroborate to current studies, releasing the strength, and creativity in every human being is the solution to poverty? Up to now, the studies result shows Angola SMEs have an inverse correlation, and that small and medium enterprise's positive influences the rate of poverty [1]. Other studies show the relationship between production and human capital, both in level and in first-order differences, shows a positive and significant statistical correlation [2]-[4]. Has human development score undoubtedly affected easing insolvency in conducting monetary improvement? Noting this probe is vital to assist enhance economic improvement.

Published on September 17, 2020.

Benjamin Korankye, School of Management, Jiangsu University, China.

Xuezhou Wen, School of Management, Jiangsu University, School of Business, Jiangnan University, China.

(corresponding e-mail: wen_xuezhou@ ${ }^{\circledR} 163 . c o m$ )
Poverty cannot be alleviated without considering some micro and macroeconomic indicators. Many studies have attested to the fact that human development has been a major contributor in eliminating this menace. These assumptions have to be understood when proper measures are put in various countries under study. The purpose is to serve the needs of an individual or a group of people. The study of [5] probes over 705 million human beings dwelling in excessive poverty (the use of the common metric of earnings much less than \$US 1.90 according to today for an individual. At the same time, other studies attest to the fact that poverty is normally measured in monetary terms, poverty, is multidimensional [6]. As such, poverty can also involve a ramification of different demanding situations beyond monetary together with functionality deprivation, marginalization, discrimination, and terrible health. And additionally, the reliance on informal relation like stakeholders to conduct groups have an impact on microbudget on assuaging poverties. Partnerships among marketers in the context of poverty (often represented by using nongovernmental agencies) and big corporations (generally multinational groups) create interactions will result in the singularity of latest and treasured possibilities for the ones concerned [7][9], used statistics on Uganda corporation to display corruption mainly the fee of gratuities negatively affect the improvement of businesses greater than the charge of taxes. However, many researchers have to find out, in alleviating poverty within the least developed countries (LDCs) calls for elevating the income level of the local people.

Human development was initially characterized as "a procedure of developing individuals' decisions" that empowers them to lead a long and sound life, to procure information, and approach assets required for a conventional way of life. In the works of [10] they discovered that China, Pakistan, Indonesia, and Nigeria are the booming close economies, and oblivious to the modern-day schemes which residents benefit through human development with resource packages. Nations with more financial improvement generally tend to have much less poverty (Beck \& Demirguc-kunt, 2007). Human development has become necessitated when it comes face of economic development in every country. [11] concluded that there is a robust worldwide measurement to the

Easmond Baah Nketia, School of Finance and Economics, Jiangsu University, China.

Godson Kweitsu, School of Management and Economics, University of Electronic Science and Technology of China, China. 
determination of national and domestic credit thriving prices that can leave to improving the needs of the people. The state of affairs baffles me when I discover most researchers do no longer evaluate problems on this by comparing some countries that are par with population size. A twenty years' panel records will be used to test by looking at the region using variables like human development index, net domestic credit, and domestic credit supplied via banks, inflation as a consumer price index, unemployment fee, and different influencing variables to check the effect. But, the effect of this human development index as a proxy for poverty has a stronger point in assisting the researchers' model to reap outcomes. The impact of net domestic credit, domestic credit mark, inflation on consumer price index, and unemployment rates have impacts on HDI which allows enhancing the assistance of people. The research will observe the poor as makers and reconnoitre the carters of higher employee wages. The study appreciates human development due to the fact they are the prime driving force of the growth of every nation and improving the standard of living in these countries. This will help readers to know the effect of human development in those international settings and additionally gives a glimpse of emerging economies.

The significance of this study area is very relevant to this research. The researchers try to identify how important the economic strength of this study area enlightens readers through other studies. In the work of [12] showed that the difficulties hindering the improvement of the Ivorian companies are threefold: (i) financing constraints, (ii) the low charge social performance factors of manufacturing (unfavorable geographical factors or inadequate funding in complementary factors together with human capital and infrastructure) (iii) and the weak spot of the personal appropriation capability (high macro and micro risks, inefficient taxation rights belongings and agreement enforcement, very little or no product improvements or loss of self-discovery, massive externalities). Cote D'Ivoire examines GDP reach 8 per cent in both 2016 and 2017 which facilitates improved their economy and had been the second quickest-growing financial system in sub-Saharan Africa in 2015, with a rate of 8.5 per cent [13]. Mozambique keeps to suffer from the results of the 2016 hidden debt crisis, but, real gross domestic product (GDP) increase decelerated to a few 7 per cents in 2017, down from 3.8 per cent in 2016 and nicely below the 7 per cent GDP increase carried out on common among 2011 and 2015. Small and medium enterprises have fallen back and their ability to generate jobs has been restricted even besides 7 per cent inflation [14]. But, Ghana's GDP for GDP increase for 2017 is predicted to have almost doubled from 3.7 percent in 2016, with about 10 per cent inflation [15]. [1] concluded on his prints display that, there is an inverse correlation, and that human development through SMEs has good impacts in lessening poverty in Angola.

The purpose of this study will also check human development to have a positive connotation of all the study areas improving the standard of living. Ghana, Cote D'Ivoire, Angola, and Mozambique are the four countries taken to check the positive impact of human development on the standard of living on poverty alleviation. Peruses will inquire as to why these countries? The analyst examines this base on their populace measure which nearly the equivalent. In the panel data analysis, these studies inquire four countries in African from using the human development index, net domestic credit, domestic credit to the private sector by banks, inflation in consumer prices, unemployment, total (percent of the total labor force) as moderating variables to check the impact of the study.

\section{RESEARCH METHODS}

Several techniques have been applied to look at human development to soften poverty using an instrumental variables method. The researchers used panel data analysis to check the correlation between the unbiased variable and the proxies of the dependent variable. At first, the correlation of the variables was analyzed to check if the variables were tied to each other.

Using Random and Fixed effects estimations, the study deploys a Hausman test to determine whether fixed or random effects are appropriate to find out how some variables interact on human development to reduce poverty in Africa. Another normality test and also using the Pesaran CD test determines if, there is cross-sectional dependence on the variables. All variables except variables in ratio forms have been transformed into natural logarithms ( $\mathrm{Ln}$ ) to help stationarity in the variance of the matrix.

$$
\begin{aligned}
& \mathcal{Y}_{\mathrm{it}}=A+\alpha_{1} \operatorname{lnpov}_{\mathrm{it}}+\alpha_{2} \operatorname{lnd} c_{\mathrm{it}}+\alpha_{3} \operatorname{lnn} d c_{\mathrm{it}}+\alpha_{4} \operatorname{lnh} d_{\mathrm{it}}+ \\
& \alpha_{5} \ln _{\ln } n_{\mathrm{it}}+\eta_{\mathrm{i}}+\mathcal{E}_{\mathrm{i}}
\end{aligned}
$$

In determining this model, the researchers estimated the model to be:

$$
Y_{\mathrm{it}}=\alpha_{\mathrm{i}}+\beta X_{\mathrm{it}}+\mu_{\mathrm{it}}
$$

which the study treats $\alpha_{\mathrm{i}}$ as fixed or random showing with the alternative hypothesis, $\alpha_{\mathrm{i}}$ correlating with the $X_{\text {it }}$ variables which after computing in the variables, the Hausman test will determine whether to choose fixed or random. The Hausman test in this hypothesized that,

Ho: random effects are independent of the explanatory variables

Ha: Ho is not true

In making this analysis, the formula was stated in equations 2 and 4 for fixed and random effects respectively.

$$
\begin{aligned}
& Y_{\mathrm{it}}=\beta_{1}+\beta_{2} X_{1 \mathrm{it}}+\beta_{3} X_{2 \mathrm{it}}+\beta_{4} X_{3 \mathrm{it}}+\beta_{5} X_{4 \mathrm{it}}+\mu_{\mathrm{it}} \\
& \beta_{1 \mathrm{it}}=\beta_{1}+\varepsilon_{\mathrm{i}} \\
& Y_{\mathrm{it}}=\beta_{1}+\beta_{2} X_{1 \mathrm{it}}+\beta_{3} X_{2 \mathrm{it}}+\beta_{4} X_{3 \mathrm{it}}+\beta_{5} X_{4 \mathrm{it}}+\omega_{\mathrm{it}}
\end{aligned}
$$




$$
\begin{aligned}
& Y_{\mathrm{it}}=\beta^{1}{ }_{\mathrm{i}}+Y_{\mathrm{i}}+\sum_{i=1}^{N-1} D_{\text {umm }}+\beta^{2} X^{2}{ }_{\mathrm{it}}+\beta^{2} X^{3}{ }_{\mathrm{it}}+ \\
& \beta^{3} X^{4}{ }_{\mathrm{it}}+\beta^{4} X^{5}{ }_{\mathrm{i}}+\mu_{\mathrm{it}} .
\end{aligned}
$$

Equation 2 and 3 shows the formula for fixed effects and 4 to 6 for a random effect.

[16] suggests that, the proxies are commonly used for the size of key consequences, for example, the human development index score is used as a proxy for poverty. As there are many determinants like economic size, financial structure, and entrepreneur market for the standard of living, primarily based on information uniformity, the study analyzes this type of relationships via employing the Human development index (HDI) which measures the development of the standard of living, net domestic credit (NDC) measuring total money given by the central banks to local banks, Domestic Credit (DC), Inflation at consumer price using annual percentage (INF) is also used to determine variables to check if there is cross-sectional dependence on these variables thereby improving the standard of living. The study then takes all these variables and construct if the diagnostic helps to establish the right results of these variables for Ghana, Cote D'Ivoire, Mozambique, and Angola. The researchers run the data to see if there is a correlation and helps to find the linear regression of the variables.

$$
P O V=\boldsymbol{\alpha}+\boldsymbol{\beta}^{1} \mathrm{NDC}_{\mathrm{it}}+\boldsymbol{\beta}^{2} \mathrm{DC}_{\mathrm{it}}+\boldsymbol{\beta}^{3} \mathrm{HD}_{\mathrm{it}}+\boldsymbol{\beta}^{4} \mathrm{INF}_{\mathrm{it}}+\varepsilon_{\mathrm{t}}
$$

where HD represents human development index using a scale of 0-1 as a unit of measurement, net domestic credit measured at a local currency; Domestic Credit by private banks measure as a percentage of Gross Domestic Product, inflation at consumer price measure using annual percentage, and unemployment rate using international labor organization percentage rate; which $\boldsymbol{\alpha}$ is the constant $\boldsymbol{\beta}$ is the beta which explains the independent variable, it is the individual time, $\mathcal{E}$ is the error term or the disturbances of independent variable and $t$ is the error term. This study leverages annual data throughout 1998-2017 based on data uniformity. The World Development Indicators (WDI) prepared by the World Bank [14]. We present the data for all our variables in Table. 1 to depict the intricate patterns in our data obtained.

\begin{tabular}{ccc} 
& TABLE 1: SoURCES OF DATA \\
\hline Variables & Unit of measurement & Source of data \\
\hline $\begin{array}{c}\text { Human development } \\
\text { index (HDI) } \\
\text { Net domestic credit } \\
\text { (NDC) }\end{array}$ & Scale 0-1 & $\begin{array}{c}\text { Human development } \\
\text { index, World bank } \\
\text { World development } \\
\text { indicators (WDI) }\end{array}$ \\
$\begin{array}{c}\text { Domestic credit (DC) } \\
\text { Inflation in consumer } \\
\text { price (INF) }\end{array}$ & Percent of GDP & WDI \\
$\begin{array}{c}\text { Unemployment rate } \\
\text { (UMP_R) }\end{array}$ & $\begin{array}{c}\text { Percent of total labor } \\
\text { force ILO estimate }\end{array}$ & WDI \\
\hline
\end{tabular}

Source: WDI and HDI, 2018.

Based on the above studies and some related work, the researcher will use the economic model using a panel data analysis posed to test the objectives of the studies.

\section{RESULTS AND DISCUSSIONS}

After confirming the correlation matrix of the panel data of all the variables under consideration in Ghana, Cote D'Ivoire, Angola, and Mozambique, it is significant to carry out fixed effects and random effects. Hausman test was run with other diagnostic tests to check the robustness of the data and results. Using a sample from 1998 to 2017 for four countries in Africa, the following results and analysis of the research were finalized.

TABLE 2: CORRELATION MATRIX

\begin{tabular}{cccccc}
\hline \multicolumn{7}{c}{ POV } & DC & HD & INF & NDC \\
\hline POV & 1.0000 & & & & \\
DC & -0.5953 & 1.0000 & & & \\
HD & -0.4765 & 0.2253 & 1.0000 & & \\
INF & -0.0998 & 0.3219 & 0.3267 & 1.0000 & \\
NDC & 0.3671 & -0.1507 & -0.1963 & -0.4753 & 1.0000 \\
\hline
\end{tabular}

NB: *** Significant at the 0.01 level, ** Significant at the 0.05 level, *Significant at the 0.1 level.

Source: Authors elaboration (2020).

From Table 2 results, the researchers conclude there is a strong relationship on the POV and NDC, DC and HD, DC and INF, and the rest the variables showing weak relation.

\begin{tabular}{ccc}
\multicolumn{3}{c}{ TABLE 3: RANDOM AND FIXED EFFECTS ESTIMATIONS } \\
\hline Variables & Fixed effects & Random effects \\
\hline DC & 0.217111 & 0.515607 \\
& $(0.113258)^{*}$ & $(0.113258)^{*}$ \\
HD & -116.5020 & -64.19011 \\
& $(28.78868)^{* * *}$ & $(28.78868)^{* * *}$ \\
INF & 0.018581 & 0.069807 \\
& $(0.011156)$ & $(0.011156)$ \\
NDC & $-8.08 \mathrm{E}-13$ & $-1.97 \mathrm{E}-12$ \\
& $(3.46 \mathrm{E}-13)^{* *}$ & $(3.46 \mathrm{E}-13)^{* *}$ \\
C & 61.869994 & 33.58997 \\
R.SQUARE & $(12.56682)^{* * *}$ & $(12.56682)^{* * *}$ \\
Adjusted R- & 0.937274 & 0.637636 \\
squared & 0.906502 & 0.618310 \\
Prob (F-statistics) & 0.000000 & 0.000000 \\
\hline NB: *** Significant at the & 0.01 level, ** Significant at the 0.05 level, \\
*Significant at the 0.1 level & \\
Source: Authors elaboration $(2020)$. &
\end{tabular}

Table 3 explains the probability estimation as 0.0000 showing a significant value at a significant level of 1 per cent. Empirical evidence from explains the variation in the credit decision for lending can help to improve the human needs in doing business [17]. Furthermore, it can be estimated that the model has an $\mathrm{R}^{2}$ of 0.937274 meaning that the independent variables under discussions can explain up to 93.7274 per cent of the situation under consideration. This attests to the study of [18] saying an argument is true when you can achieve results. However, the independent variables DC, NDC, INF, and HD show a strong relationship when using a significant at 1 per cent, 5 per cent, and 10 per cent

The estimation tosses out the nearness of a relationship between the individual effects and the independent variables at the 1 per cent level. Along these lines the null hypotheses of the Random effect model are is rejected with the alternative hypothesis of the Fixed effect model is appropriate is accepted, 
meaning the model for this examination is to be estimated with fixed effects estimations.

\begin{tabular}{lll}
\multicolumn{3}{c}{ TABle 4: Hausman TeSt } \\
\hline Test Summary & Chi-Sq. Statistics & Chi-Sq. D.f. Prob. \\
\hline Period random & 13.769553 & 40.0081
\end{tabular}

NB: *** Significant at the 0.01 level, ** Significant at the 0.05 level,

*Significant at the 0.1 level

Source: Authors elaboration (2020).

In Table 4, probabilities for Fisher tests are calculated using asymptotic Chi-square distribution. All other tests assume asymptotic normality. This was inline with other studies which demonstrate all values in the parentheses are the probability values for the tests which helps in achieving results.

\begin{tabular}{cccc}
\multicolumn{4}{c}{ TABLE 5: DiagnOSTIC TEST } \\
\hline Test & Statistics & Prob. & Decision \\
\hline $\begin{array}{c}\text { Breusch-Pagan } \\
\text { LM }\end{array}$ & 29.84385 & $0.0000^{* * *}$ & $\begin{array}{c}\text { No Serial } \\
\text { Correlation } \\
\text { No Cross } \\
\text { Section } \\
\text { Pesaran CD }\end{array}$ \\
NORMALITY & -0.517215 & $0.0000^{* * *}$ & $\begin{array}{c}\text { Series are } \\
\text { Normally } \\
\text { Distributed }\end{array}$ \\
\hline
\end{tabular}

Note: * means it's significant at $0.01, * *$ means are significant at 0.05 and $* * *$ means it's significant at 0.001 .

Source: Authors elaboration (2020).

On the other hand, analysis from the normality test in Table 5 shows series are normally distributed. With this analysis, this study follows the normal distribution and we, therefore, accept the null hypothesis whiles, the Pesaran CD test shows no crosssection dependence.

The results of the robustness checks with the instrument are reported in Tables 4 and 5. Using Breusch-Pagan LM, Pesaran CD test, normality as a diagnostic test to check the authenticity of the results and data. This confirms the appropriateness of the estimation techniques and that the model has been well specified.

\section{CONCLUSIONS}

This section includes managerial implications, limitations, future suggestions, and conclusions. The results of this study offer some strategic implications for human development have an impact on improving the standard of livings in African contest with the private sector and government playing a major role. The understanding of variables is imperative since it helps in developing the right strategies. Having said that, this study is the best thing to do for the benefit of mankind. This seems to suggest that human development offer the needs of the private banks in Ghana, Cote D'Ivoire, Mozambique, and Angola is influenced by net domestic credit, domestic credit, and inflation at consumer price and the unemployment rate in this study area. There is a need to use existing research to help combat human development policies to improve the standard of living to ensure sustainable economic development. Diverse methodologies have to be put in place to handle this challenge of human development policies in Ghana, Cote D'Ivoire, Mozambique, and Angola. Developing nations should have research institutions to conduct more investigations on the type of good human development policies on banks to ensure the sustainability of banks to increase growth and reduce poverty in these regions.

The research was limited by the generality of the result. The results of the study were based on a sample of four countries in Africa with a target population from 25 million to 30 million, and also not including other Africa countries' policies on human development. However, these financial institutions comprise a substantial proportion of the Ghanaian contest business market, and they are said to contribute about 70 percent to Ghana's gross domestic product and account for about 92 percent of businesses in Ghana. A second limitation concerns the measures used for both micro factors (bankspecific) and macro factors (country-specific) in the modeling analysis. The study considers a few variables which affect the private sector at bank-specific and country-specific determinants of a bank's credit on human development needs which other variables were excluded. It does not address all credit determinants from the supply side. These additional factors and credit delivery cycles surely deserve attention in future research on human development needs through lending processes of large and small banks, which are mostly contributing to a good standard of living in alleviating poverty.

To conclude, with the four countries under study, the researcher deduce POV, NDC, DC, INF, and HDI show a significant level of 5 per cent and 10 per cent there is a positive relationship on the dependent variable POV as the proxy for poverty which makes it positive and therefore helps to improve the standard of living. The researcher finds out that there is also a cross-sectional dependency on the variables showing positive results. According to the four countries under study, net domestic credit and human development are random and fixedly helps to improve the standard of living. Finally, the study shows a positive and significant effect of human development in Ghana, Cote D'Ivoire, Mozambique, and Angola on a standard of living.

\section{AVAILABILITY OF DATA AND MATERIALS}

All the data used are available in the World Development Indicator (WDI, 2018) and Human Development Index, World Bank (2018).

\section{AUTHOR'S CONTRIBUTIONS}

Korankye Benjamin did the write-up, collected the data, and then analyzed the result as a student under the supervision of Wen Xuezhou. Wen Xuezhou supervised the work, Easmon Baah Nketia read, made the necessary correction, and Godson Kweitsu drafted the manuscript for submission. Both authors read and approved the final manuscript. 


\section{REFERENCES}

[1] Kipanda RT. The importance of Small and Medium Business Enterprises to the economy of Angola. 2012.

[2] De La Fuente Á DA. Human capital in growth regressions: how much difference does data quality make? J Eur Econ Assoc. 2006;4(1):1-36.

[3] De La Fuente Á DA. A Human capital in growth regressions: how much difference does data quality make? 2000;(No 262).

[4] Temple J. A positive effect of human capital on growth. Economics Letters. 1999;65:131-134.

[5] Szarfenberg D hab. R. Inequality and Poverty: Analysis and Policy [Internet]. Warsaw; 2018. Available from: http://rszarf.ips.uw.edu.pl/inequality/.

[6] Misturelli F, Heffernan C. The concept of poverty: a synchronic perspective. 2010;1:35-58. Available from: https://journals.sagepub.com/doi/abs/10.1177/146499340901000103.

[7] Calton JM, Werhane PH, Hartman LP, Bevan D. Building Partnerships to Create Social and Economic Value at the Base of the Global Development Pyramid. J Bus Ethics. 2013;(117):721-33.

[8] Stuart L. Hart and Clayton M. Christensen. The Great Leap Driving Innovation From the Base of the Pyramid. MIT Sloan Management Review; 2003.

[9] Seelos C, Mair J. Social entrepreneurship : Creating new business models to serve the poor. Bus Horiz [Internet]. 2005;(48):241-6. Available from: www.elsevier.com/locate/bushor\%0ASocial.

[10] Omoruyi E, Olamide K, Gomolemo G, Donath O. Entrepreneurship and Economic Growth : Does Entrepreneurship Bolster Economic Expansion in Africa ? 2017;6(4).

[11] Lane PR, Mcquade P. Domestic credit growth and international capital flows. Scand J Econ. 2014;116(1):218-52.

[12] Kouadio H. Mp r a. 2017;(79055).

[13] World Bank. The World Bank Annual Report 2017. 2017;87. Available from: https://openknowledge.worldbank.org/handle/10986/27986.

[14] WDI. World development Indicators. World Bank [Internet]. 2018;(2018). Available from: http://datatopics.worldbank.org/worlddevelopment-indicators/.

[15] Henry Kerali. Ghana's 2018 Economic Outlook Positive but Challenges Remain. World Bank [Internet]. 2018;(2018/094/AFR). Available from: https://www.worldbank.org/en/news/press-release/2018/03/05/.

[16] Gaganis C, Pasiouras F, Voulgari F, Driver C, Muñoz-bugarin J, Growth DI, et al. SC. World Dev [Internet]. Second edi. 2018 Apr;3(2):1-21. Available from: https://doi.org/10.1016/j.chieco.2018.07.006.

[17] Boushnak E, Rageb MA, Ragab AA, Sakr AM. Factors Influencing Credit Decision for Lending SMEs : A Case Study on National Bank of Egypt. 2018;5:1-17.

[18] Thomas D. Intra-Household Resource Allocation An Inferential Approach. 2012;25(4):635-64. 